\title{
Zastosowanie natryskiwania cieplnego na przykładzie silnika turbinowego
}

\section{Thermal spraying use in the example of turbine engine}

\section{Streszczenie}

Przedstawiono informacje dotyczące systemu areologicznego natryskiwania cieplnego, omówiono jego istotę i odmiany, przedstawiono ich modele funkcjonalne i fizyczne. Omówiono różnice między właściwościami systemu elementów i właściwościami sumy elementów systemu areologicznego. Zaproponowano wprowadzenie pojęcia współczynnika synergizmu do oceny jakości systemu i do kwantyfikowania właściwości systemu. Podano kilka przykładów współczynnika synergizmu technologii.

\section{Proces natryskiwania cieplnego w WSK Rzeszów}

Wytwórnia Sprzętu Komunikacyjnego „PZL-Rzeszów" S.A. w Rzeszowie jest jednym z największych zakładów branży lotniczej w Polsce, produkującym lotnicze silniki turbinowe i odrzutowe oraz zespoły przenoszenia napędu dla śmigłowców. Przy produkcji napędów lotniczych wymagane jest stosowanie najnowocześniejszych technologii wytwarzania, do których należy m.in. technologia natryskiwania cieplnego.

Początki technologii natryskiwania cieplnego w WSK sięgają już lat 50. XX w., kiedy to do regeneracji wymiarów części maszyn stosowano prosty gazowy pistolet do natryskiwania drutem. W Zakładzie Remontowym proces nazywany był shoopowaniem.

Prawdziwy początek stosowania procesu natryskiwania cieplnego w WSK Rzeszów związany jest z zakupem w 1978 r. zestawu urządzeń do natryskiwania firmy Metco (rys. 1).

Dr inż. Stanisław Dudek, dr inż. Tadeusz Gancarczyk, mgr inż. Paweł Sosnowy - WSK „PZL - Rzeszów” S.A.

\section{Abstract}

The principles of areology system of thermal spraying on done, the essence of areological system of thermal spraying was described and the functional and physic models of areological system was presented. The difference between properties of elements system and properties of the sum of system elements was discussed. On propose to introduce the synergism of coefficient to valuation of quality of areological system and to qualification of properties system. On done some examples of synergism of coefficient of technology.
W skład zestawu wchodziły następujące elementy:

- system natryskiwania plazmowego 7M,

- system natryskiwania płomieniowego proszkiem 6P,

- system natryskiwania płomieniowego drutem 12E,

- system wentylacyjny,

- układ mocowania części (oś pozioma i pionowa),

- układ przesuwu palników,

- kabina dźwiękochłonna.

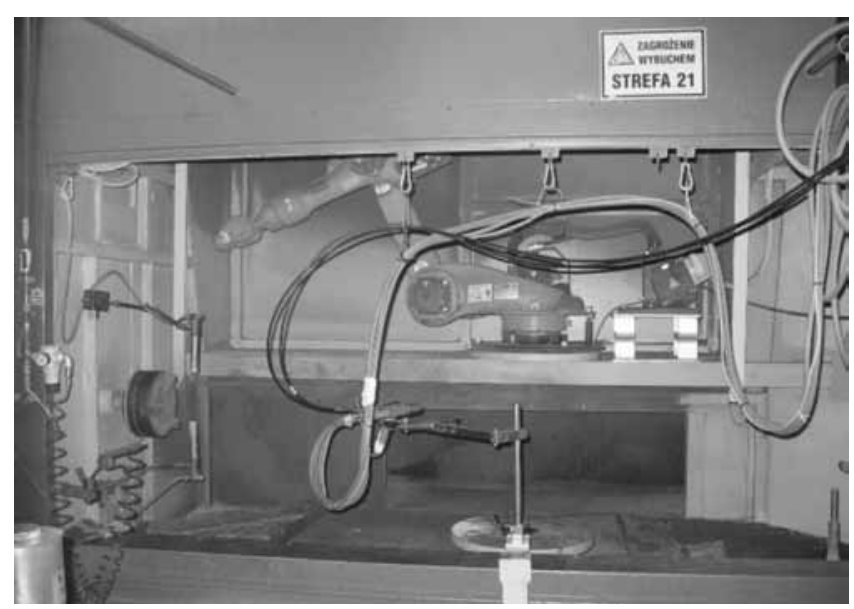

Rys. 1. System do natryskiwania cieplnego firmy Metco Fig. 1. Metco thermal spraying system 
System natryskiwania plazmowego 7M składa się z następujących elementów:

- źródła prądu 7MR (rys. 2),

- konsoli sterującej 7MC,

- podajnika proszku $3 \mathrm{MP}$,

- chłodnicy,

- pistoletów 3K, 7MB oraz 7 MXT (rys. 3).

System natryskiwania płomieniowego proszkiem składa się z szafy sterującej przepływami gazów, podajnika proszku 3 MP oraz pistoletu 6P (rys. 4).

System natryskiwania płomieniowego drutem obejmuje szafę sterującą przepływami gazów procesowych oraz dwa pistolety - ręczny $10 \mathrm{E}$ oraz maszynowy $5 \mathrm{~K}$. Pistolet ręczny wyposażony jest w pneumatyczny podajnik drutu, natomiast palnik maszynowy zawiera podajnik z silnikiem elektrycznym. Obydwa palniki umożliwiają natryskiwanie powłok $z$ drutów o średnicach 1,6 oraz 3,2 mm, a także prętów o średnicy $6 \mathrm{~mm}$. Operator podczas procesu natryskiwania przebywał bezpośrednio w kabinie i był wyposażony w sprzęt ochrony osobistej.

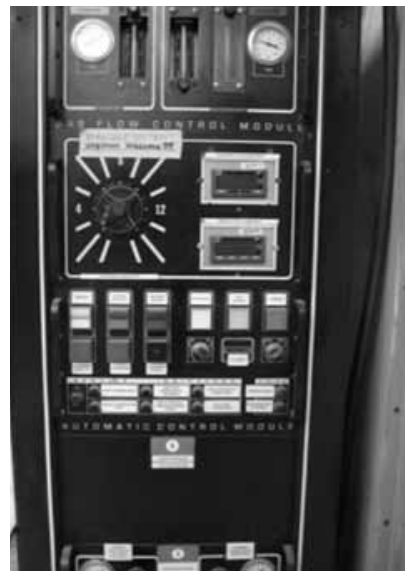

Rys. 2. Szafa sterownicza 7MR Fig. 2. 7MR Control box
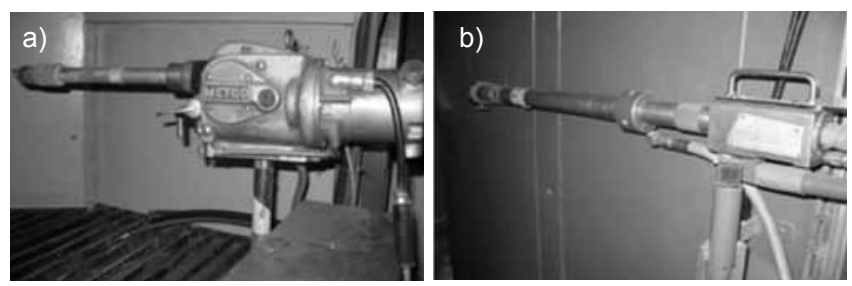

Rys. 3. Pistolety do natryskiwania: a) płomieniowego $3 \mathrm{~K}$, b) plazmowego $7 \mathrm{MB}$

Fig. 3. Spraying guns: a) for flame spraying $3 K$, b) for plasma spraying $7 \mathrm{MP}$

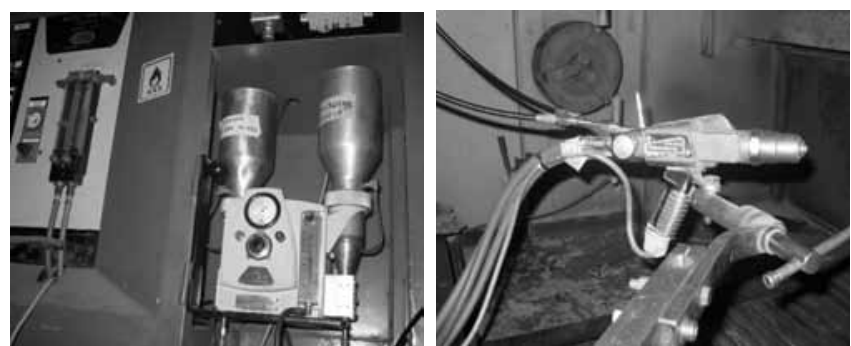

Rys. 4. Podajnik proszku $3 \mathrm{M}$ oraz pistolet $6 \mathrm{P}$ stosowane $\mathrm{w}$ procesie natryskiwania płomieniowego

Fig. 4. Powder suplier $3 \mathrm{M}$ and gun $6 \mathrm{P}$ used in flame spraying
Urządzenia te były wykorzystywane zarówno do procesów regeneracji, jak i do wytwarzania powłok na częściach produkcyjnych. System natryskiwania plazmowego był stosowany do wytwarzania powłok z proszków metalicznych oraz ceramicznych.

Wykorzystując posiadany sprzęt, opracowano parametry wytwarzania ceramicznych powłok uszczelniających dla tytanowych kadłubów sprężarki silnika TWD 10B. W początkowym etapie powłoka uszczelniająca wykonywana była metodą natryskiwania płomieniowego ze spiekanych prętów. Proces ten wymagał natryskiwania powłok na połówkach części ze względu na konieczność użycia pistoletu $5 \mathrm{~K}$. We współpracy z Politechniką Wrocławską opracowano technologię wytwarzania proszku Grafit-Nikiel, a następnie technologię plazmowego natryskiwania powłoki uszczelniającej dla kadłubów sprężarki. Powłoki uszczelniające z proszków Nikiel-Grafit oraz $\mathrm{Ni}-\mathrm{Cr}-\mathrm{BN}$ na średnice zewnętrzne natryskiwano za pomocą pistoletu płomieniowego proszkowego 6P.

W 1995 r. zakupiono w firmie Sulzer Metco system A3000 S do natryskiwania plazmowego (rys. 5).

System zawierał następujące elementy:

- dźwiękoszczelną kabinę do natryskiwania,

- stół obrotowy z możliwością przechyłu,

- robota do manewrowania i realizacji ruchu palnika w procesie natryskiwania,

- źródło prądu,

- wymiennik ciepła,

- komputerowe sterowanie A3000,

- podajnik proszku,

- pistolety plazmowe F4 MB i SM F1,

- pistolet CDS 100 do procesu natryskiwania HVOF.

W 2011 r. system ten został zmodernizowany do systemu MultiCoat - w miejsce pistoletu CDS 100 zainstalowano pistolet 6PII do natryskiwania płomieniowego.

Kolejne systemy do natryskiwania cieplnego kupowano już po prywatyzacji firmy. WSK „PZL-Rzeszów” S.A. od 2002 roku jest częścią światowego koncernu United Technologies. W 2005 r. zakupiono nowoczesny system natryskiwania cieplnego firmy Sulzer Met-

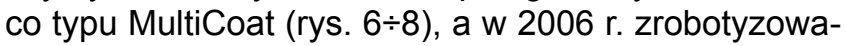
ny system natryskiwania z firmy Thermico.

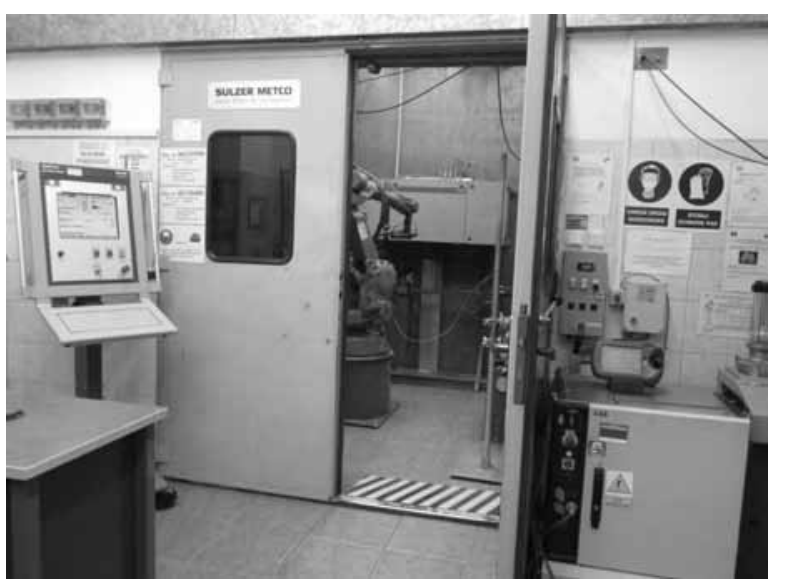

Rys. 5. System automatyczny do wykonywania powłok APS i HVOF Fig. 5. Automatic station for APS and HVOF spraying 


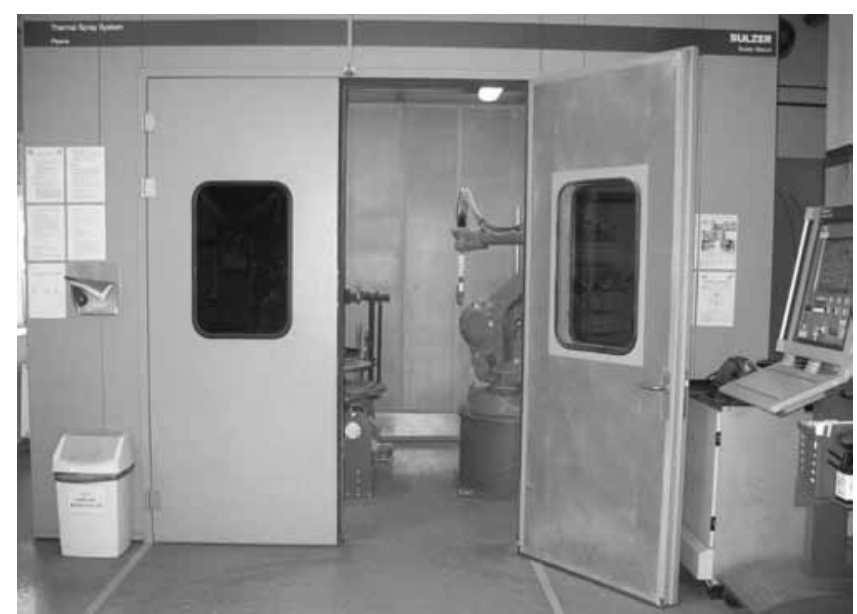

Rys. 6. System do natryskiwania plazmowego metodą APS - MultiCoat firmy Sulzer Metco

Fig. 6. View of station for APS plasma spraying - MultiCoat by Sulzer Metco

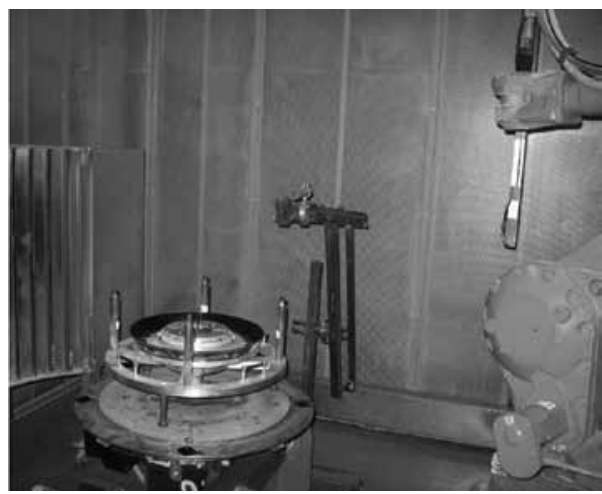

Rys. 7. Wyposażenie kabiny do natryskiwania Fig. 7. Spraying cabin equipment

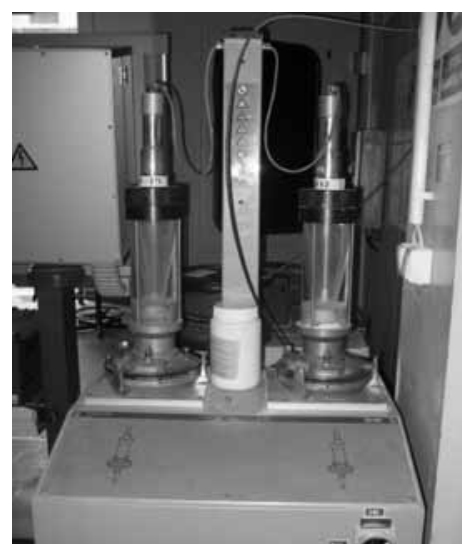

Rys. 8. Podajnik proszku TWIN 120A

Fig. 8. TWIN 120A powder supplier

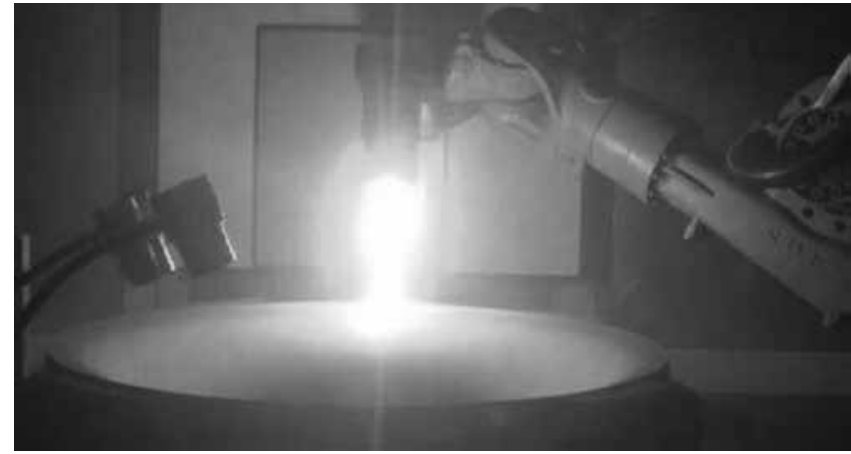

Rys. 9. System Thermico wyposażony w pistolet $A 60$ podczas pracy Fig. 9. Thermico system with A60 gun during work
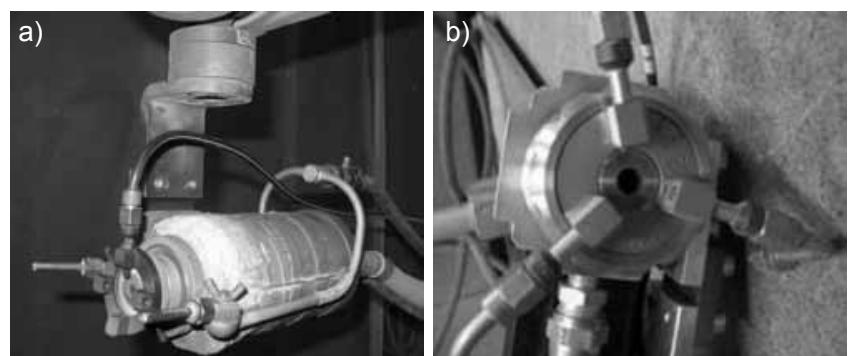

Rys. 10. Pistolet: a) jednokatodowy F4MB, b) trójkatodowy Triplex PRO200

Fig. 10. One-cathode gun F4MB (a) and three-cathode gun Triplet PRO200 (b)

Kolejny system MultiCoat został zakupiony w 2009 r., a w 2010 r. zakupiono trójelektrodowy pistolet Triplex PRO 200. Obecnie dostępne są 4 nowoczesne systemy natryskiwania - 3 z firmy Sulzer Metco i jeden z Thermico (rys. 9).

Systemy te wyposażone są w palniki plazmowe jednokatodowe F4 MB, SMF1 i A60 oraz w pistolet trójkatodowy Triplex PRO 200 (rys. 10).

Wszystkie systemy do procesu natryskiwania są całkowicie zautomatyzowane, wyposażone w manipulatory i sterowane komputerowo. Proces natryskiwania realizuje zadany program.

\section{Przykłady powłok natryskiwanych w silniku lotniczym}

Nowoczesne silniki lotnicze stawiaja przed konstruktorami wysokie wymagania związane $z$ warunkami pracy. $Z$ tego powodu, w celu obniżenia kosztów materiałowych oraz poprawy parametrów użytkowych części silnikowych, stosuje się powłoki wytwarzane metodą natryskiwania cieplnego. Powłoki te znajduja zastosowanie we wszystkich modułach silnika lotniczego. Typowe powłoki stosowane w podstawowych modułach silników produkowanych w WSK Rzeszów są przedstawione na rysunku 11: wentylator (powłoka uszczelniająca, powłoka odporna na korozję), sprężarka (powłoka odporna na korozję i erozję), komora spalania (powłoka typu bariera termiczna), turbina (powłokowa bariera cieplna).

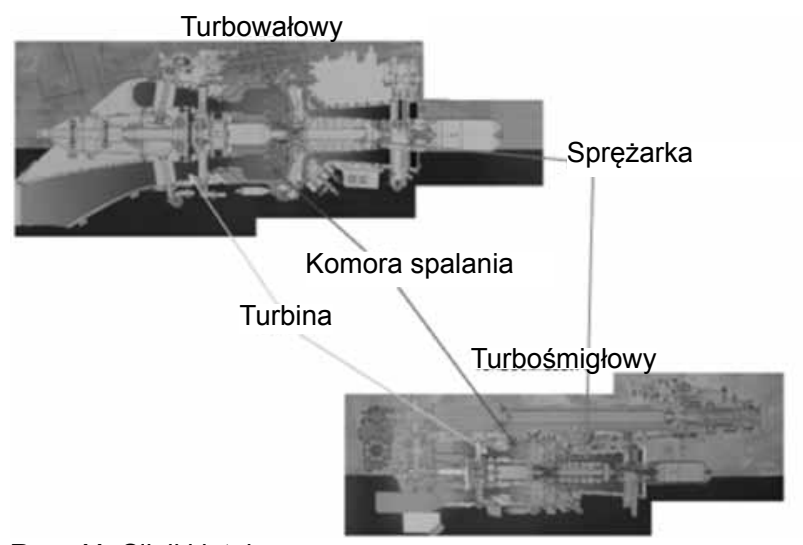

Rys. 11. Silniki lotnicze

Fig. 11. Aircraft engine 

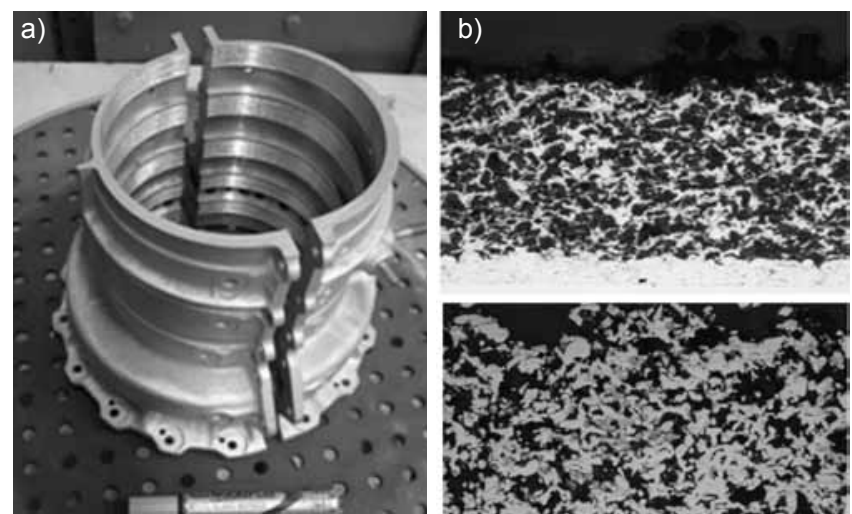

Rys. 12. a) Kadłub sprężarki osiowej, b) powłoka uszczelniająca Fig. 12. Axial-flow compressor body (a) and seal coating (b)

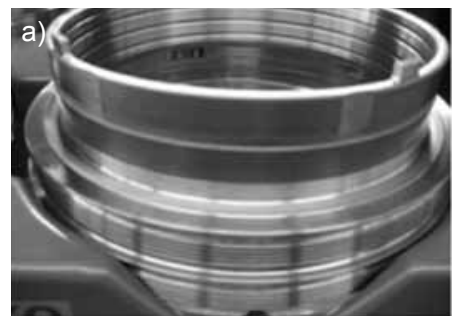

Rys. 13. a) Tuleja łożyska, b) powłoka antyerozyjna

Fig. 13. Bering sleeve (a) and erosion resistance coating (b)
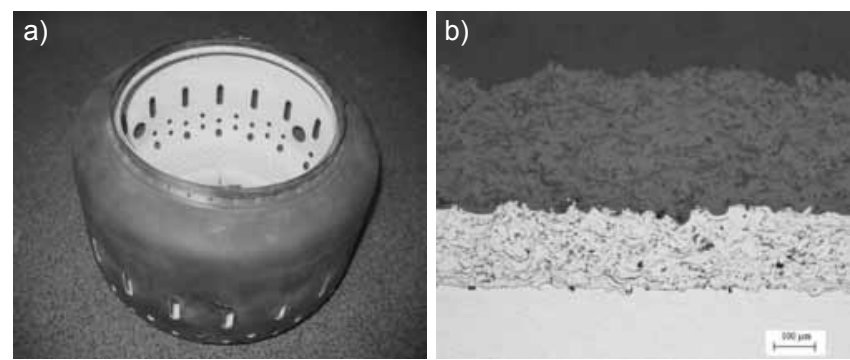

Rys. 14. a) Komora spalania silnika PZL 10W, b) powłoka TBC Fig. 14. Combustion chamber in PZL 10W engine (a) and TBC coating (b)

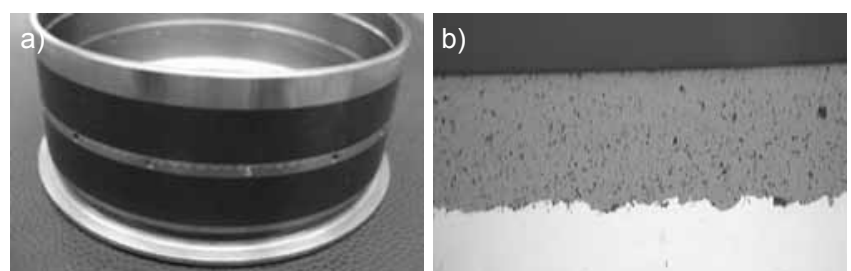

Rys. 15. a) Tuleja uszczelnienia układu olejowego, b) powłoka tlenkowa

Fig. 15. Sleeve for lubrication system (a) and oxygen coating (b)
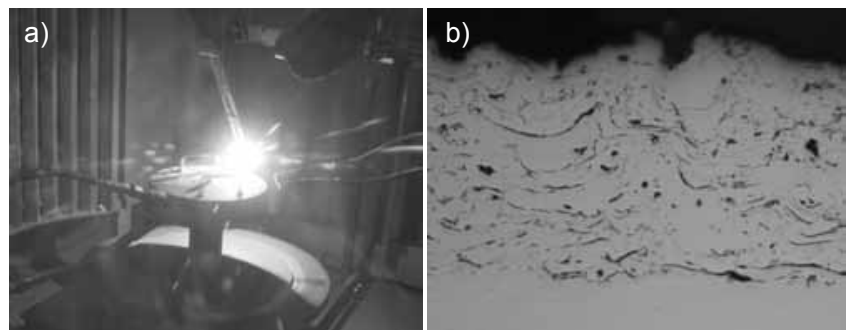

Rys. 16. a) Proces regeneracji średnicy bazowej, b) powłoka molibdenowa

Fig. 16. Process of base diameter regeneration (a) and molybdenum coating (b)
Na rysunku 12a przedstawiono kadłub sprężarki osiowej z powłoką uszczelniającą natryskiwaną cieplnie (rys. 12b). Rysunek 13a przedstawia tuleję łożyska z powłoką antyerozyjną (rys. 13b).

Komora spalania silnika PZL 10W jest pokazana na rysunku 14a, a mikrostruktura natryśniętej powłoki typu bariera cieplna na rysunku 14b. Tuleja uszczelnienia układu olejowego z nałożoną powłoką tlenkową jest widoczna na rysunku 15.

$\mathrm{Na}$ rysunku 16a przedstawiono proces regeneracji średnicy bazowej części przy użyciu procesu natryskiwania plazmowego. Materiałem użytym do regeneracji jest proszek molibdenowy. Mikrostrukturę wykonanej powłoki przedstawiono na rysunku $16 \mathrm{~b}$.

\section{Kontrola powłok}

Wraz z rozwojem powłok natryskiwanych równolegle następował rozwój zaplecza laboratoryjnego. Laboratorium metalograficzne umożliwia ocenę powłok natryskiwanych zarówno pod kątem sprawdzenia przyczepności powłoki do podłoża, jak i oceny mikrostruktury powłoki.

W celu zapewnienia właściwej oceny mikrostruktury powłok natryskiwanych opracowano zestaw parametrów szlifowania i polerowania zgładów metalograficznych. Do przygotowania zgładów stosowane są urządzenia firm Struers i Mettech (rys. 17).

Kontrola powłok otrzymanych w procesie natryskiwania prowadzona jest dwuetapowo:

- ocena mikrostruktury dokonywana jest drogą badań metalograficznych na próbkach wykonywanych równocześnie z procesem nakładania powłok na części,

- ocena wykonanej powłoki na części obejmuje pomiar grubości powłoki, położenia na części oraz stanu powierzchni (porowatość zewnętrzna, mikropęknięcia, przyczepność).
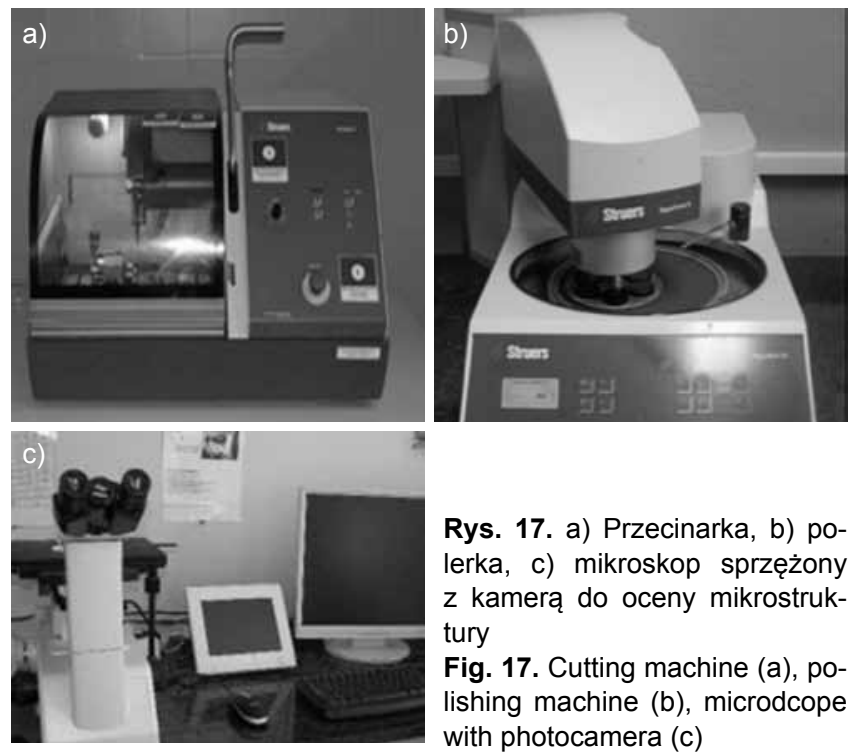

Rys. 17. a) Przecinarka, b) polerka, c) mikroskop sprzężony z kamerą do oceny mikrostruktury

Fig. 17. Cutting machine (a), polishing machine (b), microdcope with photocamera (c) 


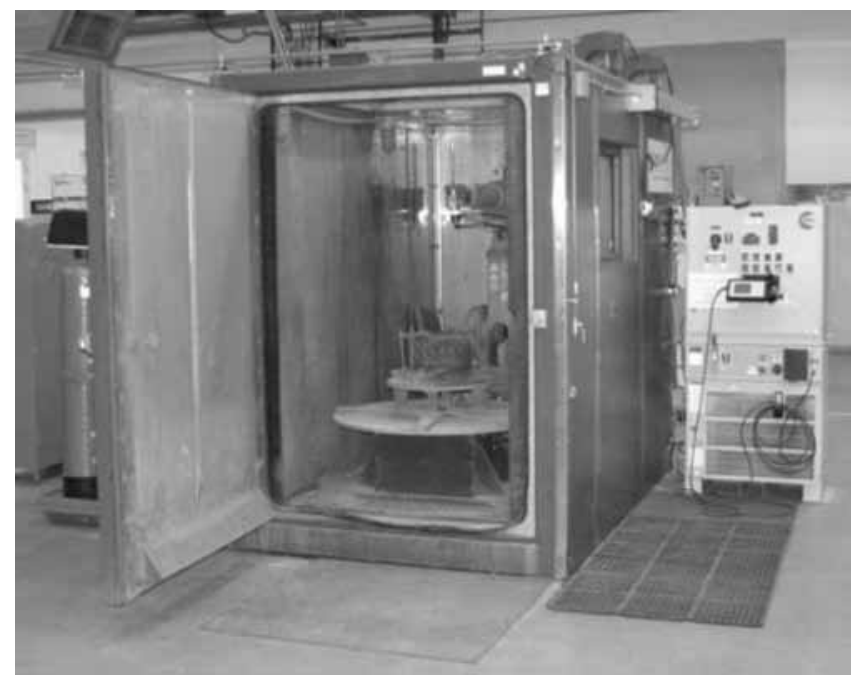

Rys. 18. Urządzenie do usuwania powłok strumieniem wody Fig. 18. Water stream station for coating removal
W przypadku stwierdzenia niezgodności właściwości powłoki z wymaganiami warunków i rysunku części wykonana powłoka jest usuwana i proces jej nanoszenia jest powtarzany.

Usuwanie wykonanych powłok wykonywane jest w zależności od kształtów części za pomocą obróbki mechanicznej, obróbki strumieniowo-ściernej lub z użyciem zrobotyzowanego systemu Water Jet (rys. 18).

System został zakupiony specjalnie w celu precyzyjnego usuwania powłok typu powłokowa bariera cieplna $(\mathrm{PBC}) \mathrm{z}$ powierzchni części blaszanych o skomplikowanych przestrzennych kształtach. Powłoka - zarówno ceramiczna, jak i metaliczna usuwana jest strumieniem wody pod wysokim ciśnieniem. Umożliwia to pełne usunięcie nałożonej powłoki bez naruszenia materiału podstawowego, co jest szczególnie istotne dla zespołów wykonanych z blach.

\section{Podsumowanie}

Oceniając zastosowanie procesu natryskiwania cieplnego na elementach silników lotniczych wykonywanych w WSK „PZL-Rzeszów” S.A., należy podkreślić, że zastosowanie powłok natryskiwanych w przemyśle lotniczym systematycznie wzrasta. Oprócz dotychczas stosowanych technologii natryskiwania - płomieniowego, plazmowego (APS, LPPS, VPS) coraz szersze zastosowanie zaczynają znajdować nowe metody natryskiwania, np. przy wytwarzaniu powłok zastępujących chrom galwaniczny natryskiwanie naddźwiękowe HVOF.

Coraz częściej stosowana jest metoda natryskiwania Cold Spraying - która wykorzystywana jest powszechnie w procesach remontowych, szczególnie dla stopów aluminium i magnezu. Metoda ta stosowana jest nie tylko do wykonywania powłok,

ale również do odbudowywania ubytków materiału części. Pozwala na obniżenie kosztów remontu, np. wykorzystywana jest w remoncie skrzynek przekładniowych. Prowadzone są również próby z zastosowaniem tej metody dla stali i stopów niklu.

W ramach rozwoju procesów natryskiwania prowadzone są również testy mające na celu opracowanie parametrów wytwarzania kolumnowej powłoki TBC (PBC) przy użyciu systemu PS PVD. Pozwoli to na znaczne obniżenie kosztów wykonania powłok kolumnowych TBC (PBC) w stosunku do obecnie stosowanej metody EB PVD.

Na podstawie przedstawionych wyników można stwierdzić, że proces natryskiwania cieplnego jest i będzie coraz szerzej stosowany w przemyśle lotniczym.

\begin{tabular}{|c|}
\hline $\begin{array}{l}\text { Spotkania Spawalników w } 2012 \\
\text { 5 Warmińsko-Mazurska Biesiada Spawalnicza } \\
\text { Piaski k. Ruciane-Nida, 13-14.06.2012, Ośrodek Exploris. } \\
\text { Zgłoszenia i informacje: Mirosława Reschke, tel.: } 585112801\end{array}$ \\
\hline $\begin{array}{l}\text { I Dolnośląskie Sympozjum Spawalnicze } \\
\text { Wrocław, 20.06.2012, Wydział Mechaniczny Politechniki Wrocławskiej. } \\
\text { Zgłoszenia i informacje: Artur Lange, e-mail: Artur.Lange@pwr.wroc.pl }\end{array}$ \\
\hline $\begin{array}{l}\text { XI Szczecińskie Seminarium Spawalnicze } \\
\text { Szczecin, 6.09.2012, Wydział Inżynierii Mechanicznej i Mechatroniki Zachodniopomorskiego Uniwersytetu Technologicznego } \\
\text { w Szczecinie. Zgłoszenia i informacje: Katarzyna Rudzka, tel.: } 914624451\end{array}$ \\
\hline $\begin{array}{l}\text { XVI Pomorskie Spotkanie Spawalników } \\
\text { Gdańsk, 13.09.2012, Wydział Mechaniczny Politechniki Gdańskiej. } \\
\text { Zgłoszenia i informacje: Iwona Janson, tel.: } 585112800\end{array}$ \\
\hline $\begin{array}{l}\text { I Kieleckie Spotkanie Spawalników } \\
\text { Kielce, 20.09.2012, Zakład Doskonalenia Zawodowego w Kielcach. } \\
\text { Zgłoszenia i informacje: Ewelina Janus, tel.: } 413687480 \text { w. } 102\end{array}$ \\
\hline $\begin{array}{l}\text { Organizatorzy } \\
\text { Linde Gaz Polska, Esab, Abicor-Binzel, Lincoln Electric, Technika Spawalnicza w Poznaniu, Urząd Dozoru Technicznego, } \\
\text { Supra-Elco, Rywal-RHC, Belse, 3M, GCE, Eckert AS, Figel, Witt, Spaw-Ekspert, Trumf, Messner Eutectic Castolin }\end{array}$ \\
\hline $\begin{array}{l}\text { Materiały konferencyjne zawierające m.in. wybrane artykuły ze spotkań zostaną opublikowane } \\
\text { w numerze 10/2012 miesięcznika naukowo-technicznego Przegląd Spawalnictwa }\end{array}$ \\
\hline
\end{tabular}

